\title{
Horizons and Conscience
}

CHRISTOPHER PLATT

Glasgow School of Art,

Mackintosh School of Architecture 
What world does a European student imagine as they look beyond the Academy towards their future professional life? What horizons can they see which we cannot? Does that picture engage their moral compass, tracking the pressing contemporary issues from Planetary Environmental Crisis to the fragility of the Global South? How do they, as members of an increasingly international community, navigate that moral complexity? When their own future is unclear, how can they design the human future? 'Horizons' could be the sixth thematic area in this conference. 'Horizons' is closely linked to 'Conscience'; the former involving looking outwards and the latter involving looking inwards.

At no other time has a student's knowledge of the world seemed greater and that same world seemed smaller than now. Their global awareness and ethical perspective has developed throughout childhood thanks to education, digital communication and access to international travel. Can meaningful work and geographic and cultural variety satisfy their outward and inward gaze? Is this the deeper motivation in joining a school of architecture? As they imagine their future, how can we help them put their values into practice and reinforce their belief that others' lives can be improved through their agency as an architect?

One answer lies in us identifying conditions of human need which can be addressed by the practical application of their innovative thinking. The Global South contains many such conditions. The pressing planetary issues have a heightened significance there because their consequences are often extreme and life-changing. It is arguably in Global South situations that a student's horizons and conscience can directly inform their work in an holistic manner.

In the last four years, small groups of students at the Mackintosh School of Architecture in Glasgow have chosen to develop two research-informed live design projects for real clients in two African countries as part of their academic programme. The first involved the design of a community sports facility in Accra, Ghana for disadvantaged teenagers. Developed in collaboration with a secondary school in Accra and a Ghana-based sports charity, their clients were three Ghanian community workers of the same generation as the students. The second project (now in its third year of development) examines student wellbeing through the design for a barrier-free student residential village for the University of Rwanda in their Huye Campus, outside Kigali. A recent collaborative MSA and UoR staff/student research-capacity building workshop in the $\mathrm{Ki}$ gali campus created the opportunity for students to begin to explore their values and agency in action. 
Available campus accommodation in Rwanda is poorly designed and constructed, resulting in cramped dormitory spaces where privacy is compromised. Students eat unhealthily (due to poverty and lack of choice) and seek employment to cover living expenses despite opportunities being scarce. This results in a lack of concentration and ability to fully focus on academic work. Horizons are severely restricted as a consequence. Conditions for able-bodied students are challenging but for those with any form of disability, it is almost unbearable. This is a project therefore where student designers from the Global North and Global South address their fellow students' difficulties by combining empathy with creativity.

Through this project, students from MSA and UoR are identifying the ideal conditions for participatory design, practice-based research and a procurement process which accommodates the highest standards of user-informed design. The health and welfare of university students is critical to their personal education and development as well as to the success of the university and country. A university can be a significant influence on the formative development of the next generation of citizens who will shape and lead that country. It should be a place where horizons and conscience are nurtured not thwarted.

This paper examines how this live internationally collaborative, research-informed design and build project in Rwanda between two schools of architecture seeks to establish a new collaborative model for procurement. It demonstrates how excellent student accommodation could be realized to meet the particular needs of student life, while also being the vehicle for educational and research opportunities. It explores how student participants are challenged to consider what their agency and practice might be in the future and what ethics might guide it. It questions how their hidden 'horizons' and 'conscience' are brought into the open to inform the process and end results of their creative endeavors, reinforcing the idea that the person of the architect can make a difference for the better. It explores how collectively and collaboratively these personal and private attributes can be seen as the foundations of a new 'hidden school' of international dimensions. 


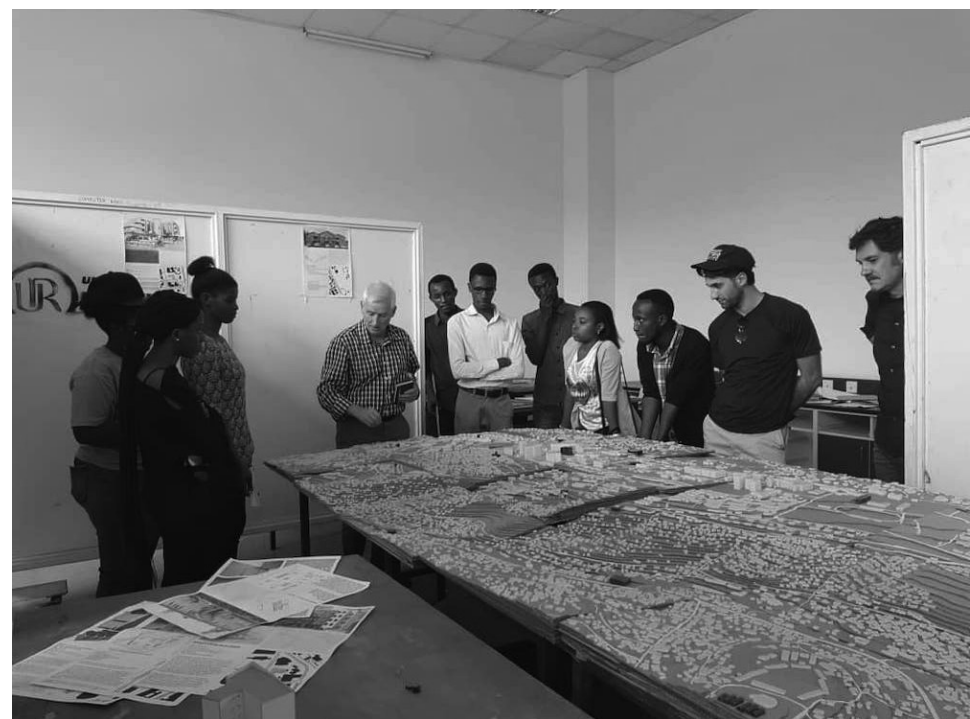

1: Discussion with students about the development of Kigali with student urban model.

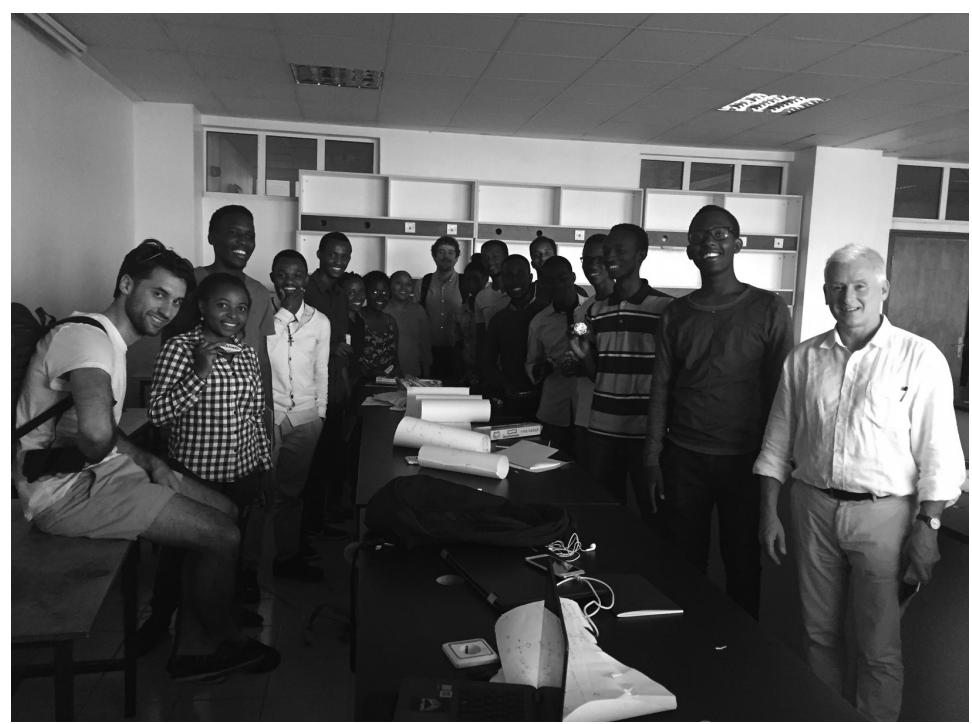

2: The Rwandan students of architecture who participated in the workshop with MSA's Christopher Platt and student Matt Robbin with Orkidstudio's CEO James Mitchell. 


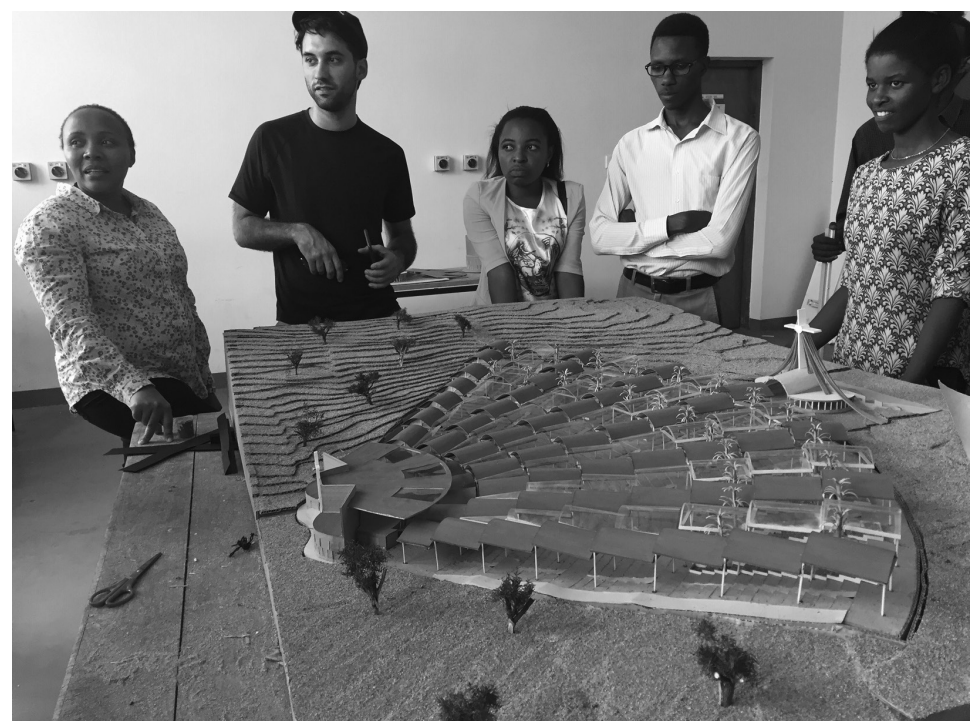

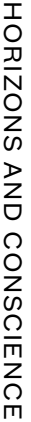

3: The beginnings of the conversation between staff and students from Scotland and Rwanda. Dr. Josephine Malonza, MSA's Matt Robbin and architecture students of the University of Rwanda.

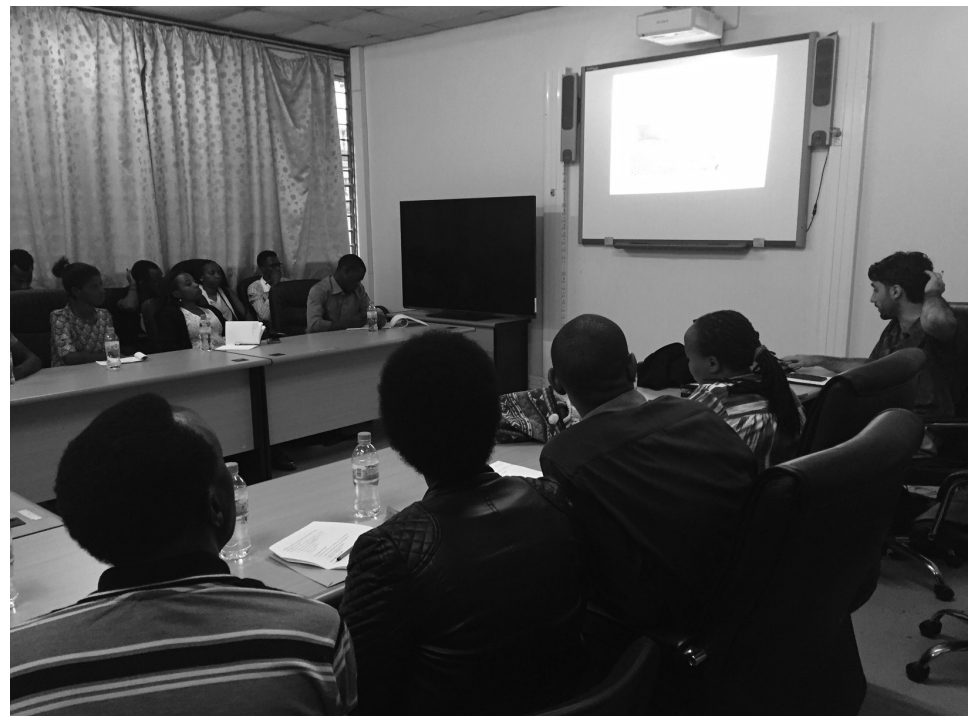

4: Matt Robbin presenting the design proposals and workshop outputs to University of Rwanda staff at their Huye campus. 
$\stackrel{5}{\frac{5}{4}}$

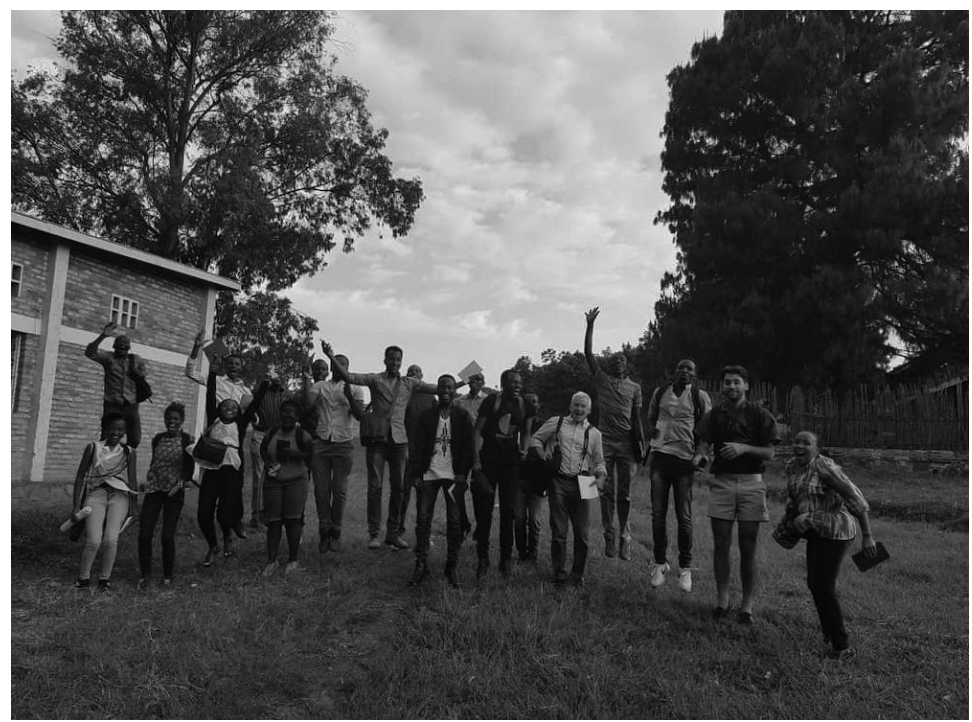

5: Staff and students at the end of the Huye campus site visit.

$\stackrel{m}{\stackrel{\infty}{\sim}}$

$山$
$U$
$z$
$w$
0
0
$z$
0
0
0
$z$
0
0
$z$
0
$N$
0
0
0
$I$ 